\title{
Risk Indviduality in Crisis Planning: the Case of Gender in Amercan Agriculture
}

\author{
DANA L.K. HOAG \\ Colorado State University \\ Professor, Agricultural and Resource Economics \\ Fort Collins, CO 80523-1172 \\ dhoag@colostate.edu \\ CATHERINE M H KESKE \\ Colorado State University \\ Assistant Professor, Soil and Crop Sciences \\ Associate Director, Institute for Livestock and Environment \\ Fort Collins, CO 80523-1170 USA \\ Catherine.Keske@colostate.edu \\ REBECCA GOLDBACH \\ Research Assistant, Agricultural and Resource Economics, \\ Fort Collins, CO 80523-1172
}

\begin{abstract}
Crisis response can be improved by accounting for differences in risk perception. We confirm that gender individuality can be an important divider by using a case study of agricultural producers. Women were more risk averse and less confident. However, we found less difference than studies have found in other sectors. Our research shows that context matters. Results will vary by geographical location. Gender is one division that should be considered in crisis planning; however, it will not always be important.
\end{abstract}

Keywords: Agriculture, Gender, Risk Management, Crisis Response.

\section{Introduction}

As related to crisis response, "risk management ... encompasses a broad range of activities to increase capacities and reduce vulnerabilities to prepare for, cope with, respond to and recover from disaster events." But exactly whose risk is being addressed? No single response plan can be universally effective since everyone perceives and reacts differently to risk. The effectiveness of a plan, however, can be improved by targeting groups when there are clear and systematic divisions or subcultures. For example, a plan for responding to extreme weather might group livestock pastoralists in Kenya differently than crop producers. It is difficult and sometimes impossible, however, to accurately aggregate, homogenize or stereotype social systems. For example, pastoralists from differing tribes might respond to risk as differently from each other as they do from crop producers. Nevertheless, it is important to develop crises response plans that properly account for the social contexts in which risks occur, especially when the differences are large and/or important ${ }^{1}$. 
A growing body of research shows that there might be a systematic division between men and women when it comes to risk. According to the Hyogo Framework for Action 2000-2015: on Building Resilience of Nations and Communities to Disaster, "a gender perspective should be integrated into all disaster risk management policies, plans and decision making processes, including those related to risk assessment, early warning, information management, and education and training. ${ }^{2}$ However, an unsettled question in the literature is whether men and women perceive and react to risk in the same way. For example, some studies show that women are more risk averse than $\mathrm{men}^{3}$ or that women are less confident. ${ }^{4}$ Others have found no differences. $^{5} \quad$ Whether differences are found likely depends on the context. If, when and where differences are found, they should be integrated into risk analysis and crises response. That is, women and men are a good example of two sub-cultures that may need very different plans as directed by the Hydro Framework for Action. However, as we will show, every case could be unique. Therefore, no category, even gender, is automatically different enough to justify unique risk planning.

Risk analysis in economics and other financial fields can be a useful guide where there can be wide differences in risk attitudes. ${ }^{6}$ The goal of this study is to apply that knowledge to examine the differences in risk perception and management between men and women in one setting that can confirm whether risk gender individuality is important to account for in crisis planning. Specifically, we examine farm or ranch opperators/producers in the United States. There is no information about risk management differences across gender in agriculture, despite the fact that U.S. Census data shows that female-operated farms are a rapidly growing component of the sector. ${ }^{7}$

We base our analysis on two surveys conducted at risk management programs in $2008 .^{8}$ Data were collected in a self assessment survey and a revealed preference survey connected to a computerized risk management simulation program called Ag Survivor. ${ }^{9}$ We examine differences between men and women in the areas of risk preference, confidence, motivation, and influence. The purpose of this particular examination is to demonstrate that differences do occur, but that gender differences in agriculture are different than gender differences in other business sectors. Due to these differences, results might not necessarily transfer to females in Kenya. However we can learn some lessons about why women and other sub-cultures might need individual attention.

\section{Literature Review}

Female business ownership has increased steadily in the United States. According to a 2006 study $^{10}$, women now own $41 \%$ of all privately held firms in the United States. Census data found that the number of women who owned businesses grew 43\% from 19901994. ${ }^{11}$ According to a 2001 article, "the relative surge of women entrepreneurs in the last decade has been nothing short of revolutionary. ${ }^{11}$ " Census data did not start differentiating male and female farm operators until 1978, but it is assumed that females have been involved in agriculture for much longer. Commercial agriculture in the United States is widely dominated by males; as of 2002 , only $5 \%$ of commercial farms in the US were operated by women. The numbers for commercial farms show greater differences in farm operation across gender than do private farms, as this is where females have been employed for decades, often as co-operators with their husbands. The number of women operated private farms is increasing. Women were principle operators of 209,784 farms. ${ }^{12}$ This number increased to 237,819 in 2002, an increase of 13.4\%. ${ }^{13}$ The National Agricultural Statistics Service created a publication entitled Women in Agriculture: Quick Facts from the 2002 Census of Agriculture which highlight women's impact on agriculture. ${ }^{14}$ The data show that female-operated farms are smaller than maleoperated farms both in acres and sales; women's farms also have a smaller average income than male farms, indicating a less favorable financial position.

Finance theory suggests that the higher the risk, the higher the expected rate of return on investment. As will be shown later, females have been found to be more risk averse than males. This would suggest that males, who have a higher risk preference, will have higher returns on their investments; thus, differences in risk taking 
propensity may help explain differences in the financial performance of male- and female-owned businesses. A 2003 study $^{5}$ found that although profits are significantly higher for males, so are the variations in profits. After adjusting for the variability associated with risk, this study found no significant differences between the performances of male- and female-owned businesses. The lower risk-taking propensity in females can also help explain the differing level of growth of male- and female-owned firms, where male-owned firms show a faster rate of growth. Based on their greater risk aversion, female entrepreneurs seem to be more concerned than male entrepreneurs with the risks associated with fast-paced growth and tend to deliberately adopt a slow and steady rate of expansion. ${ }^{15}$

It has also been found that women accumulate less savings for retirement and that this may, at least in part, be connected to their risk preferences. ${ }^{16}$ A 1998 study ${ }^{16}$ displays how risk aversion can affect wealth accumulation later in life, and that women's lower risk preference may result in their having less wealth in retirement then men. Their review of the literature finds that when wealth equals $\$ 20,000$, single women are predicted to hold $43 \%$ of that wealth in risky assets and single men are predicted to hold $51 \%$ of their wealth in risky assets. When wealth increases to $\$ 100,000$, both sexes will allocate a greater percentage into risky assets but for males this increase is greater than for women (an increase for women of $19 \%$ and an increase for men of $28 \%)$.

One study looked at differences across gender related to the optimal storage rule. ${ }^{17}$ The results from this analysis were as follows: women sell less often than men, men sell earlier than women, and the longer a producer stores the lower the price the producer is expected to receive. The authors state that the most likely explanation for women having fewer sales than men is that men gain more utility from trading than women. In other words, the authors attribute this difference to men's higher propensity to enjoy competition. Overall, the authors found that because women store longer, they tend to make 1.4 cents less per bushel than men.

\subsection{Risk Preference}

Past research, based on finance theory, found that greater risk-taking preferences are positively correlated to performance in small firms; however, this past research has defined performance in terms of sales and profit. When results are controlled for risk and the variations in financial profit caused by risk, differences in performance between genders disappear. Women appear to be more risk averse than men. ${ }^{3,18}$ Studies found that females stay in the market less across all levels of cost than males, indicating that females have a lower risk preference. ${ }^{18}$

\subsection{Confidence}

Studies have also found that women are less confident and estimate a higher likelihood of the negative outcome, making them less likely to take the risk. ${ }^{4}$ Psychological studies show that most people are overconfident about their own relative abilities, and this overconfidence affects business performance. Research on confidence and business performance has found that overconfidence is not necessarily a good thing, ${ }^{19}$ finding that overconfidence can lead individuals to undertake activities that are not in their best interest. Research has also shown that men are more overconfident than women..$^{20,21}$ One study that finds such results is Grain Price Expectations of Illinois Farmers and Grain Merchandisers. $^{22}$ These researchers found that the phenomenon of overconfidence holds in their sample

\subsection{Motivation}

Individual motivations can highly influence business success. Studies found that women indicate their most important entrepreneurial motivations are: desire for challenge, self-determination and desire to balance family and work responsibilities. For women, profits and growth were important, but not as important as the above-stated motivators. In contrast, male entrepreneurs were most motivated by the need to improve their positions in society for themselves and their families. ${ }^{23}$ "If females' main motivations are not sales and growth, it could explain some of the performance gap between the genders. However, 
research on women entrepreneurs has found differences in motivations across women. ${ }^{24-27}$

\subsection{Influence}

According to one study, "for decades, researchers in various domains of the bio-behavioral sciences have had an enduring affinity for the idea of the dominant male....Females, by contrast, are often portrayed as being far less aggressive, more communal, and less interested in social politics. $^{28 "}$ If this statement is true, it might affect how individuals influence the decisionmaking process in their business. An individual's influence over business decisions will affect their ability to impact the performance of their operation. Research indicates that males exert more influence over the decision making process. ${ }^{29}$ The literature confirmed many common gender findings, such as men describing themselves as having a higher ability to influence others, and peers viewing males as having higher influencing ability. ${ }^{28}$

\section{Research Methods}

The data in this study was collected from agricultural producers that live and work in Colorado. Two survey instruments were developed and administered to measure gender differences in agricultural producers. The first instrument, a selfassessment survey, asked questions about how individuals perceive themselves with regard to risk preferences and decision-making variables. The second survey was a revealed behavior instrument developed to accompany a computerized simulation game called Ag Survivor, ${ }^{9}$ which simulates realistic farm management decisions. Using experimental risk preferences based on a computer simulation to compare risk seeking by females and males has been done before. ${ }^{18}$ We agreed with these authors that a computerized approach was the best option because it "reduces the likelihood of gender effects from peer group pressure, public performance and perception of others relative to self. ${ }^{18 "}$

Four hypotheses were developed that correspond to the four areas where we found differences between men and women in the literature:
1. H1: RISK AVERSION: Women show more risk aversion than men.

2. H2: CONFIDENCE: Women will display less confidence about their decisions than men

3. H3: MOTIVATION: Women are less motivated by profit than men

4. H4: INFLUENCE: Women will have less influence than men.

Each survey addressed these four hypotheses. The self-assessment survey assigned a numerical scoring system using a scale of one to five for 10 questions. The Ag Survivor survey ranked individual risk preference on a scale of zero to three, and confidence on a Likert scale of one to five based on the way each survey respondent played the Ag Survivor scenario. The averages of scores for both surveys were compared across gender and analyzed using a one-and/or twosample t-test assuming unequal variances in Microsoft Excel.

There were 82 usable Self-Assessment surveys and 81 useable Ag Survivor surveys. The Self-Assessment survey included 61 females (74\%) and 21 males (26\%). The Ag Survivor survey had a more equal distribution with 44 females (54\%) and 37 males (46\%). A summary of the participant demographics is presented in Table 1. Three demographic variables were collected: age, number of children, and marital status. Marital status was the only statistically significant variable that was different between the genders. Sixtyfive men and 45 women reported their age on the survey, with the male average age being 45 years and the female average 48 years. The male age range was 23-77 years, while the female age range was 21-84 years. Sixty-one men and 45 women reported their number of offspring. The average number of children for males was 1.8 while the average number for females was 1.4. The range of children was also similar across gender, with males ranging from 0-6 children and females ranging from $0-5$ children. 


\begin{tabular}{|c|c|c|}
\hline & Male & Female \\
\hline Average Age & 45 & 48 \\
\hline Percent Married & 81 & 57 \\
\hline $\begin{array}{c}\text { Average Number of } \\
\text { Children }\end{array}$ & 1.8 & 1.4 \\
\hline
\end{tabular}

Table 1: Demographic Features of Survey Respondents

\subsection{Self-Assessment Survey}

The Self-Assessment survey was administered to individuals at risk conferences around Northern Colorado. To conceal their identity, but link the two surveys, individuals were assigned a common number for the self-assessment surveys and the Ag Survivor survey. A linked number also saved subjects the trouble of filling out demographic information twice.

The Self-Assessment survey consisted of ten questions, some of which had multiple parts, leading to 16 individual parts. Two of the parts aimed to assess whether the individual had a business partner and, if so, what relationship the partner had with them (spouse, friend, etc.). Five of the parts asked individuals questions about their investment portfolio or about hypothetical investments they could make. There was also an investment question asking about the business partner's investment portfolio. Two questions asked about the respondent's perceived capability of running the business alone, one about the individuals perceived capability and another about their business partner's capability. There was also a part addressing with overall business satisfaction, influence, correctness of decisions made, positive motivations, and negative motivations for the respondent's actual business. The survey ended with a question asking individuals who they seek input from when making a business decision.

\subsection{Ag Survivor Survey}

The revealed behavior, Ag Survivor survey was administered at the same conferences as the SelfAssessment survey. At each of these conferences, individuals participated in a farm computer-simulation program called Ag Survivor. ${ }^{9}$ Participants were asked to track both their group decisions and the decisions they would have made had they been acting on their own. The survey also asked participants to document how confident they were in their decisions. Surveys were administered at conferences that used different versions of the Ag Survivor game, so the decisions had to be normalized across versions to allow comparison across conferences. The conferences had different versions since the Ag Survivor program is targeted to provide realistic risk management decisions to different groups. Participants played the Lazy U Ranch scenario (about sheep) at four conferences, the King Family Ranch (about cattle ranching) at one conference, and The Wheatfields (wheat farming) at two conferences.

The Ag Survivor program ${ }^{9}$ is an innovative risk research and education effort to help farm managers understand and explore risk management decisions and evaluate the financial consequences of those decisions with the presence of risk. Ag Survivor uses real world farm/ranch settings, probabilities, and impacts to depict the financial effects of risk. Participants must make management decisions for the operation through several decision making periods. After each period, random outcomes are generated based on probability and the management teams receive updated prices, yield information, inventories, etc. Risk management decisions included buying and storing hay for the winter, buying crop insurance, forward pricing, and hiring a shepherd to guard sheep from predators. A brief description of each program is provided below.

All three scenarios are set up over two years of decisions, with each year having four periods and each period involving one to four decisions. The Lazy U Ranch is a hypothetical sheep operation in the mountains of Colorado, which runs 1500 head of ewes in a range flock operation utilizing a mixture of public and private land. Each year, participants may choose one of three options for marketing their lamb crop: forward contract weaned lambs to a feedlot for October delivery, sell weaned lambs to a feedlot on the October cash market, or retain ownership of the weaned lambs through the feedlot and sell them on the February cash market for slaughter. The King Family Ranch is a hypothetical cow/calf/hay operation in the mountains of 
Colorado. They raise 350 acres of hay each year and use much of their production as winter feed for their 500 cows. They typically calve in March-April and sell weaned calves in October. The Wheatfields is a hypothetical wheat/fallow farming operation in eastern Colorado. They farm 6,000 acres of farmland, typically harvesting 3,000 acres of winter wheat annually. They also have 100 head of cows that typically calve in March-April with weaned calves sold in October.

\section{Results}

\subsection{Risk Preferences}

Three questions in the self-assessment survey addressed risk preferences. Two of three questions, 1 and 5, showed no statistical difference between men and women. Question 1 asked about the riskiness of the respondent's investment portfolio. Both male and female agricultural producers report their investment portfolio to contain very little or little risk. Selfassessment question 5 asked individuals to select between four investment choices that presented different risk levels.

On the other hand, self-assessment question 4 asked individuals to list their financial investment portfolio by levels of risky assets. When the averages of males and females were compared, the p-value was significant using a one-tailed test but not significant using a twotailed test. The two-tailed test would be significant at 0.10 .

When the male and female averages were compared in the Ag Survivor survey, using a two sample t-test assuming unequal variances, the p-value was significant and showed women are slightly more risk averse than men. Considering all results from both surveys, women show a slightly higher aversion to risk than men.

\subsection{Confidence}

There was no statistically significant difference in the questions directly aimed at differences in male and female confidence. However, when asked about their capability of taking over the business if a partner became unable to, men scored significantly higher. Therefore, males stated that they feel more capable about taking over the business on their own. It is believed that an individual's confidence will affect their perceived personal capabilities; specifically, the higher an individuals' confidence the more capable their perception of oneself. The literature indicates that males are more confident than females, which would lead to males perceiving themselves as more capable than females. Our combined results indicate that men show some signs of more confidence, but less so than implied in studies of other types of businesses.

\subsection{Influence}

We also analyzed whether there was a gender difference in perceived influence over the business decision making process. The influence score for males was 2.76, while the influence score for females was 2.72, which presented no significant difference. This contradicts previous literature, ${ }^{28,29}$ their findings indicate that males will exert more influence than females.

\subsection{Motivation}

We examined a total of 12 potential places where we might find different motivations between men and women:

Negative motivations: Receiving a poor price, Producing a low yield, Not having enough money for retirement, Having to add an additional employee to the operation, Facing a legal action against you, You or your business partner getting sick/injured and not able to work.

Positive motivations: Growth of business, Savings for children's future, Sense of accomplishment or recognition, Cushion to deal with illness or injury, To make ends meet, Independence

Only three variables showed significant differences. Males were more motivated to avoid the risk of a poor price and poor yield than females. Therefore, men place more value on avoiding low profits than women. Female operated farms have been found to have a lower net income than male farms. If females are less motivated to reduce the risk of a poor price or yield, instead valuing other motivators as greater influences, it 
could help explain this difference in net income. The other significant variable was that men are more concerned saving for their children's future.

\section{Discussion}

There appears to be some differences in risk preferences between men and women, although they do not appear very strong. Some questions did not reveal any statistical difference between risk preferences, but differences were measurable in one question on the self assessment survey and in behavior as men and women played the Ag Survivor scenarios. Men were more confident than women in only one way, their perceived capability of taking over the business on one's own.

In terms of motivation, men were found to be statistically different from women in three cases. Men were much more concerned about poor prices or yields, which are highly related to profits, than women. Finally, there appears to be no difference in influence when it comes to agricultural producers.

Our purpose was to take a close look at whether female and male agricultural producers in the United States had significant differences in the way they perceive and react to risk. Based on the body of literature from other studies, we should have found bigger differences. We can only speculate, but perhaps agricultural women have fewer differences because they, like most men, grew up on a farm or ranch and are therefore relatively comfortable with how the property is managed. This shows, circumstantially, that context matters and that results will therefore be very different from one location to the next. Returning to our example of Kenyan pastoralists, women have an extremely less say in management issues than American women, ${ }^{30}$ and face different risks if catastrophe strikes. About 40 percent of smallholder households are managed by women and women are the primary managers of small livestock such as poultry and goats. Despite their role in managing livestock, they hold title to less than 1 percent of the land and are often purposefully excluded from making management decisions. ${ }^{30}$ Female-headed households have lower income and are more vulnerable than other households. Therefore, it is imperative that the unique risk needs of these women be individually investigated and addressed to assure that their welfare is equally addressed in any crisis response plan.

\section{References}

1. Center for Disaster Preparedness. Integrating gender into community based disaster risk management. (Community Based Disaster Risk Management: Training and Learning Circle- Philippines, 2009).

2. Hyogo Framework for Action 2005-2015: Building the Resilience of Nations and Communities to Disasters. (World Conference on Disaster Reduction, Kobe, Japan, 18-22 January 2005)

3. L. Karakowsky and A. Elangovan. Risky Decision Making in Mixed-Gender Teams: Whose Risk Tolerance Matters? Small Group Research 32(1) (2001) 94-111

4. Gysler, M., J. Kruse, and R. Schubert. Ambiguity and Gender Differences in Financial Decision Making: An Experimental Examination of Competence and Confidence Effects. Center for Economic Research, Swiss Federal Institute of Technology, Working Paper $02-23$. (http://ideas.repec.org/p/eth/wpswif/0223.html\#provider,2002).

5. J. Watson and S. Robinson. Adjusting for Risk in Comparing the Performances of Male- and Female-Controlled SMEs. Journal of Business Venturing 18(6) (2003) 773-788

6. J. Pennings, B. Wansink and M. Meulenberg. A note on modeling consumer reactions to a crisis: The case of the mad cow disease. Intern. J. of Research in Marketing 19(1) (2002) 91-100.

7. U.S. Census. National Agricultural Statistics Service, U.S. Department of Agriculture. 2007

8. R. Goldbach. Gender Influence Of Agricultural Performance. Masters Thesis, Department of Agricultural and Resource Economics, Colorado State University, Fort Collins, (2008).

9. D. Hoag. Applied Risk Management in Agriculture. CRC Press, Taylor \& Francis Group, Boca Raton, Florida, USA (2010) 403 p. 
10. J. Cohoon and W. Aspray. The State of Social Science Research on Gender and IT Entrepreneurship. National Center for Women and Information Technology Entrepreneurial Report Series 5, (2006)

11. S. Weiler and A. Bernasek. Dodging the Glass Ceiling? Networks and the New Wave of Women Entrepreneurs. The Social Science Journal 38(1) (2001) 85-103

12. US Census. National Agricultural Statistics Service, U.S. Department of Agriculture. 1997

13. US Census. National Agricultural Statistics Service, U.S. Department of Agriculture. 2002

14. National Agricultural Statistics Service. Women in Ag Quick Factos (2002 Census of Agriculture (Ref. 13))

15. G. Johnson, R. McMahon. Owner-Manager Gender, Financial Performance and Business Growth amongst SMEs from Australia's Business Longitudinal Survey. International Small Business Journal 23(2) (2005) 115-142

16. N. Jianakoplos, and A. Bernasek, Are Women More Risk Averse? Economic Inquiry 36(4) (1998) 620-630.

17. L. Cunningham, Brorsen, B., Anderson, K., and Tostao, E. (2007). Gender Differences in Marketing Styles, Agricultural Economics 38(1) 1-7.

18. M. Powell and D. Ansic. Gender Differences in Risk Behavior in Financial Decision Making: An Experimental Analysis. Journal of Economic Psychology 18(6) (1997) 605-628

19. C. Camerer and Lovallo, D. Overconfidence and Excess Entry: An Experimental Approach. The American Economic Review 89(1) (1997) 306-318

20. B. Barber and Odean, T. 2001. Boys will be boys: Gender, Overconfidence, and Common Stock Investment. The Quarterly Journal of Economics 116 (1) (2001): 261-292

21. C. Bengtsson, Persson, M., and Willenhag P. 2004. Gender and Overconfidence. Journal of Economic Letters. 86(2) 199-203.

22. J. Eales, Engel, B., Hauser, R., Thompson, S. Grain Price Expectations of Illinois Farmers and Grain Merchandisers. American J. of Agricultural Economics 72(3) (1990) 701-708
23. H. Buttner and D. Moore. Women's Organizational Exodus to Entrepreneurship: Self-Reported Motivations and Correlates with Success. Journal of Small Business and Management 35(1) (1997) 34-46.

24. J. Harwood, R. Heifner, K. Coble, J. Perry, and A. Somwaru. Managing Risk in Farming: Concepts, Research, and Analysis. U.S. Department of Agriculture, Agricultural economics Report \# 774 (Washington DC. 1999)

25. J.E. Cliff. Does One Size Fit All? Exploring the Relationship between Attitudes Towards Growth, Gender, and Business Size. Journal of Business Venturing. 13(6)(1998) 523-542.

26. G. Powell and K. Eddleston, The Paradox of the Contented Female Business Owner. Journal of Vocational Behavior 73(1) (2008) 24-36

27. E. Doty, Tomkiewicz, J. Bass, K.. Sex Differences in Motivational Traits and Ethical Decision Making among Graduating Accounting Majors. College Student Journal 39(4) (2005) 817-826

28. P. Hawley, T. Little, and N. Card. The Myth of the Alpha Male: A New Look at DominanceRelated Beliefs and Behaviors among Adolescent Males and Females. International Journal of behavioral Development 32(1) (2008) 76-88.

29. S. Colarelli, J. Spranger, and R. Hechanova. Women, Power, Sex Composition in Small Groups: an Evolutionary Perspective. Journal of Organizational Behavior 27(2) (2006) 163184

30. United States Government: Feed the Future Initiative. Kenya FY 2010 Implementation Plan. Www.feedthefutue.gov (accessed January 22, 2011). 